so on. These are special place selections, and even for them it will surely be necessary to prove that parent sequences admitting such place selection actually exist. The author assures us that A. $H$. Copeland and A. Wald have found satisfactory answers to such questions as these.

All the same, to the present reviewer, a von Mises sequence is merely a sample sequence, extended to infinity, for the coin or other object, and is only one of an aggregate of sample sequences characteristic of the object. A sample of what? There's the rub; we are brought back to the a priori. And why bar the door so strenuously to sequences other than the postulated random ones? Systematic sequences, for example, 010101 . . ., are imaginable, as well as sequences which, in respect of the same coin or object, may not have the same limit $p$. The desirable thing would be to deduce the sequences from a priori conditions, and to show that the exceptional ones, which we may, if we please, call non-random (though the concept of randomness becomes unnecessary), are of zero measure in the aggregate of possible sequences.

Such views, which are put forward here for what they are worth, are in no way intended to disparage the book, which is a most valuable addition, from any point of view, to the literature of statistics and probability.
A. C. A.

\title{
DEVELOPMENT IN ETHIOPIA
}

\section{Ethiopia}

An Empire in the Making. By Ferdinando Quaranta. Pp. $\mathbf{x x}+120+23$ plates. (London : P. S. King and Son, Ltd., 1939.) 7s. 6d. net.

$\mathrm{W}_{\text {th }}^{\mathrm{s}}$ E have to go back to the days of Rome for the mode of development inaugurated by Italy in its new Empire of Ethiopia. It started with road-making, on which at one time 60,000 Italians were employed, and already more than 3,000 miles of macadamized highways have been built out of 7,000 miles planned. At the same time the Italian scientific societies were mobilized to collect and tabulate the facts relating to earth, air and water. Lake Tana is stated to be of little importance to the Nile floods. Alluvial gold was discovered and is now being worked, but there is no likelihood of rich reefs. Platinum seems possibly to be of more importance, and there was also discovered copper and iron ores, but no petroleum. The fauna and flora were surveyed in connexion with their adaptation to various altitudes and meteorological conditions.

Meantime, Castellani's wonderful health service of the war had been converted into a permanent organization for the country with a first-class research laboratory adapted to pathology and parasitology at Addis Ababa and hospitals in each of the four provinces which were created; about eight hundred qualified medical officers are employed. Surveying the collected facts, Italy granted twelve billion lire ( $£ 133$ million) to be spread over some years for special development. Agricultural veterinary and forestry services were established with experimental stations in each province, these governed and manned by university-trained officers. In the civil administration we deduce that the method employed is an army to keep the peace, with specially trained civilians whose duty is mainly the development of the country. There is little information on the administration, but the education and health of the natives seem to be an especial care. Meantime large areas of land in the high plateaux were found derelict, much of it the former property of Ras Makonnen, and steps were taken to colonize it. Upwards of a thousand Italian families have been here settled, growing grain, coffee, cotton and a host of minor products. For some years this immigration may be almost indefinitely increased by the introduction of regular cultivation in place of the alternate clearing and fallowing of the land employed by the natives. To this end a commission is at work investigating titles to land so far as they exist.

The technique of the Italians throughout would seem to be that of a large business firm rather than the haphazard method usually adopted in British colonies, where development is in the first instance confined to what already exists, usually by the increased employment of the old methods. Scientific men are only called upon when some pest appears or there is a shortage of food, the basal facts required for their employ being still unknown. We can recall no instance where the State has boldly capitalized development and colonization, the great settlement hoped for in East Africa at the beginning of the century having degenerated into the formation of large ranches worked by native labour, a condition paralleled all the way south to the Cape. Here in Ethiopia, if success be ultimately achieved, may be seen the commencement of a planned "Dominion" rather than a "Colony", the successful result of which would be of profound world importance. J. S. G. 